\title{
Le miroir coprologique à deux faces !
}

\author{
F. Klotz \\ (C) Springer-Verlag France 2011
}

Cent mille milliards de germes de plus de 400 espèces constituent la flore intestinale résidente de tout être humain. Cette flore commensale est un écosystème complexe permettant le bon fonctionnement intestinal et s'opposant à la multiplication d'agents pathogènes exogènes.

Cette barrière spécifique associée aux composants physicochimiques et immunologiques de la paroi intestinale est cependant fragile. Les agents pathogènes s'ingénient à vaincre la flore protectrice, à franchir le mucus, à adhérer aux entérocytes, interférant ainsi avec la flore résidente et perturbant les mécanismes intimes des entérocytes.

Ces agents pathogènes sont ceux du péril fécal et constituent la face sombre du " miroir coprologique », qui s'intéresse surtout aux régions pauvres, à l'hygiène fécale défaillante, avec une cible particulièrement constituée par les enfants en bas âge. Ces diarrhées aiguës entraînent une mortalité qui peut être impressionnante, passant de 3,9 décès pour 100000 aux États-Unis à 10 à 50 pour 1000 dans les pays en voie de développement. Chiffres impressionnants qui se traduisent par quatre à cinq millions de décès par an.

Cette mise à mal de la flore intestinale résidente par des bactéries, des virus ou des parasites est surtout due à la pauvreté et peut être combattue par des mesures préventives simples : le lavage des mains et la construction de latrines étant les principales clefs de la lutte contre ce fléau.
L'autre face du miroir coprologique est ensoleillée et originale, elle reflète une méthode simple de traitement des diarrhées chroniques rebelles dues à Clostridium difficile et a été décrite par plusieurs équipes américaines. En effet, près de 1500 malades âgés meurent, chaque année aux États-Unis, de diarrhée chronique à $C$. difficile résistantes à tout traitement. Il s'agit d'une technique de « transplantation fécale » qui agit comme « un probiotique naturel ». Une colonisation bactérienne est obtenue par la transplantation par coloscopie de matières fécales traitées de membres de la famille du patient, qui sont déposées par coloscopie dans le cæcum et l'iléon terminal. Une reconstitution de la flore fécale est ainsi obtenue avec un taux de réussite très important [1].

Ainsi, les fèces peuvent être à l'origine du pire comme du meilleur ; du péril fécal dévastateur à la transplantation fécale salvatrice. C'est le côté insolite de la nature et le volet passionnant de la médecine moderne qui progressent parfois à partir de concepts très simples !

\section{Référence}

1. Yoon S, Brandt LJ (2010) Treatment of refractory/recurrent C. difficile-associated disease by donated stool transplanted via colonoscopy: a case series of 12 patients. J Clin Gastroenterol 44(8):562-6 